\title{
Eclampsia: an enigma
}

\section{Chitra Joshi $^{1 *}$, Deepa Hatwal' ${ }^{2}$, Zehra Mohsin ${ }^{3}$}

\author{
${ }^{1}$ Department of Obstetrics \& Gynaecology, V.C.S.G. Government Medical Sciences \& Research Institute, Srinagar \\ Garhwal, Pauri Garhwal, Uttarakhand, India \\ ${ }^{2}$ Department of Pathology, V.C.S.G. Government Medical Sciences \& Research Institute, Srinagar Garhwal, Pauri \\ Garhwal, Uttarakhand, India \\ ${ }^{3}$ Department of Obstetrics \& Gynaecology, J. N. M. C. A. M. U, Aligarh, Uttar Pradesh, India
}

Received: 26 January 2016

Accepted: 20 February 2016

\author{
*Correspondence: \\ Dr. Chitra Joshi, \\ E-mail: cjobs@hotmail.com
}

Copyright: ( ) the author(s), publisher and licensee Medip Academy. This is an open-access article distributed under the terms of the Creative Commons Attribution Non-Commercial License, which permits unrestricted non-commercial use, distribution, and reproduction in any medium, provided the original work is properly cited.

\begin{abstract}
Background: Eclampsia is the commonest cause of convulsions in pregnancy next being epilepsy. Incidence varies from 1 in 100 to 1 in 2000 pregnancies. Eclampsia accounts for 24\% of all maternal deaths in India. Eclampsia is a significant cause of perinatal mortality and morbidity in non-industrialised countries (up to $40 \%$ perinatal deaths).

Methods: We are reporting a retrospective study on the patients of eclampsia attending a tertiary care hospital. The study included 3907 deliveries conducted in VCSG Govt. Medical Science \& Research Institute, Srinagar, Pauri Garhwal, Uttarakhand from April 2012 to Sep. 2014.

Results: The total number of eclampsia cases was 98 . The antepartum eclampsia cases were 87 and the postpartum eclampsia cases were 11.The incidence of antepartum eclampsia was $2.22 \%$ (87/3907) at our center. The total number of maternal deaths due to eclampsia was 6. The total Case Fatality Rate was $11.11 \%(6 / 57)$. There were 6 early neonatal deaths most commonly due to prematurity. There were 20 (22.99\%) intrauterine deaths.

Conclusions: Early prediction and diagnosis requires high index of suspicion and comprehensive training of health professionals at all levels of health care. The answer to poor management of eclampsia lies in better education and training of all obstetricians, anesthetists, midwives, and general practitioners in the diagnosis and treatment of severe pre-eclampsia and eclampsia.
\end{abstract}

Keywords: Pre- Eclampsia, Eclampsia, Epilepsy, Maternal mortality rate

\section{INTRODUCTION}

Pre-eclampsia is defined by the International Society for the Study of Hypertension in Pregnancy as gestational hypertension of at least $140 / 90 \mathrm{mmHg}$ on two separate occasions $\geq 4$ hours apart accompanied by significant proteinuria of at least $300 \mathrm{mg}$ in a 24 hour collection of urine, arising de novo after the $20^{\text {th }}$ week of gestation in a previously normotensive woman and resolving completely by the $6^{\text {th }}$ postpartum week. Hypertensive disorders complicating pregnancy are common and form one of the deadly triad, along with haemorrhage and infection.
Pre-eclampsia is a pregnancy specific syndrome characterised by hypertension (>140/90 $\mathrm{mm}$ of $\mathrm{Hg}$ ) and proteinuria $\left(300 \mathrm{mg} / 24 \mathrm{hr}\right.$. urine). ${ }^{1}$ It is the commonest cause of convulsions in pregnancy next being epilepsy. ${ }^{2}$ Incidence varies from 1 in 100 to 1 in 2000 pregnancies. $^{3}$ It can be antepartum, intrapartum or postpartum. Eclampsia has profound effects on cardiovascular, renal, haematological, respiratory and neurovascular systems, which leads to very high maternal morbidity and mortality. ${ }^{4}$ Eclampsia accounts for $24 \%$ of all maternal deaths in India. ${ }^{5}$ Eclampsia is a significant cause of perinatal mortality and morbidity in non-industrialised countries (up to $40 \%$ perinatal deaths). ${ }^{6}$ 
We conducted a retrospective study in the patients of eclampsia attending a tertiary care hospital to identify a crucial step or link to decrease the morbidity and mortality in developing countries.

\section{METHODS}

This is a retrospective study conducted from April 2012 to September 2014 at a tertiary care center and results were analyzed. This study was conducted to report the incidence of eclampsia in developing countries and to analyze the cases in reference to age, parity, antenatal care, and gestational age. The study included 3907 deliveries conducted between this period and 98 cases were diagnosed for eclampsia. This study also concludes the fetomaternal outcome in eclampsia. The occurrence of convulsions that cannot be attributed to other causes, associated with signs of pre-eclampsia during pregnancy, labor or within 7 days of delivery were diagnosed as having eclampsia. The hospital records between the above periods were reviewed by a team of consultants and senior residents in the department of Obstetrics and Gynecology. The study was conducted with permission from the hospital ethics committee.

\section{RESULTS}

Table 1: Distribution of patients $(n=87)$ according to age (years).

\begin{tabular}{|lll|}
\hline Age (In years) & Number of cases & Percentage (\%) \\
\hline$<20$ & 6 & 6.89 \\
\hline $21-25$ & 66 & 75.86 \\
\hline $26-30$ & 12 & 13.79 \\
\hline $31-35$ & 1 & 1.14 \\
\hline $36-40$ & 0 & 0 \\
\hline$>40$ & 2 & 2.29 \\
\hline $\mathrm{N}$ & 87 & 100 \\
\hline
\end{tabular}

Table 2: Distribution of patients according to different obstetrical components.

\begin{tabular}{|l|l|}
\hline Factors & Number of cases \\
\hline Parity & \\
\hline Primigravida & 61 \\
\hline Multigravida & 26 \\
\hline Gestational Age (in weeks) & \\
\hline$<28$ & 4 \\
\hline $28-34$ & 25 \\
\hline$>34$ & 58 \\
\hline Mode of delivery & \\
\hline Normal vaginal delivery & 52 \\
\hline Assisted vaginal delivery & 6 \\
\hline Caesarean section (c/s) & 29 \\
\hline
\end{tabular}

The study included 3907 deliveries conducted between this period. The total number of eclampsia cases was 98 .
The antepartum eclampsia (APE) cases were 87 and the postpartum eclampsia (PPE) cases were 11.The incidence of APE was $2.22 \%(87 / 3907)$ of all deliveries conducted at our centre. Only one patient was a booked case and all other cases were unbooked. Most number of eclampsia cases was in the 21-25 year age group with $75.86 \%$ incidence while in women older than 36 years only 2 cases reported with an incidence of $2.29 \%$ (Table 1 ).

Table 3: Fetal outcome.

\begin{tabular}{|lll|}
\hline Outcome & Number & Percentage \\
\hline Intrauterine deaths & 20 & 22.99 \\
\hline Apgar score $\leq 6 / 10$ & 24 & 27.59 \\
\hline Apgar score $\geq 7 / 10$ & 43 & 49.42 \\
\hline
\end{tabular}

Table 4: Comparison of our eclampsia study with other studies.

\begin{tabular}{|llll|}
\hline Parameters & $\begin{array}{l}\text { Our } \\
\text { Study }\end{array}$ & Swain et al & Sultana et al \\
\hline Incidence (\%) & 2.2 & 2.2 & 3.23 \\
\hline Age in years & $20-25$ & $<20$ & $25-34$ \\
\hline $\begin{array}{l}\text { Primigravida } \\
(\%)\end{array}$ & 71.27 & 84 & 43 \\
\hline $\begin{array}{l}\text { Unbooked } \\
\text { status (\%) }\end{array}$ & 1.14 & 2.27 & 4.47 \\
\hline $\begin{array}{l}\text { Gestational } \\
\text { age (in weeks) }\end{array}$ & 36 & 36 & 36 \\
\hline $\begin{array}{l}\text { Mode of } \\
\text { delivery (\%) }\end{array}$ & 66.66 & - & 53 \\
\cline { 2 - 3 } & 33.33 & - & 47 \\
$\begin{array}{l}\text { Caesarean } \\
\text { section }\end{array}$ & 11.11 & 29.5 & 10.29 \\
\hline $\begin{array}{l}\text { Maternal } \\
\text { deaths }\end{array}$ & 11.2 & 13.9 & 23.52 \\
\hline $\begin{array}{l}\text { Neonatal } \\
\text { deaths }\end{array}$ & 22.4 & 25 & - \\
\hline $\begin{array}{l}\text { Intrauterine } \\
\text { deaths (IUD) }\end{array}$ & 27.58 & 53.48 & - \\
\hline Birth anoxia & & \\
\hline
\end{tabular}

The study indicated that it's a disease of primigravida with 61 cases out of 87 with $70.11 \%$ incidence. In multigravida 12 cases reported with an incidence of $13.79 \%$. Women at either end of reproductive age were found to be more susceptible. At a gestational age of more than 34 weeks 58 cases were diagnosed with eclampsia as compared to only 4 cases in less than 28 weeks. Out of 87 cases of eclampsia, 52 cases $(59.77 \%$ delivered by normal labour 29 cases $(33.33 \%)$ undergone LSCS and in 6 cases $(6.89 \%)$ assisted vaginal delivery was conducted (Table 2).

Majority of patients landed in caesarian section due to non-progress of labour (NPOL). The other indications were fetal distress, breech presentation, obstructed labour and uncontrolled hypertension (HTN). Most common labour complication was atonic $\mathrm{PPH}$, which was mostly 
managed by conservative measures. One patient was given B-lynch and 1 patient landed in caesarian hysterectomy. There were 6 maternal deaths due to eclampsia. The most common cause of maternal mortality in was placental abruption. The total Case Fatality Rate (CFR) was $11.11 \%(6 / 57)$. There were six early neonatal deaths. Most common cause for neonatal deaths was prematurity. There were $20(22.99 \%)$ intrauterine deaths (IUDs) indicating lack of prenatal care and delayed referral (Table 3).

\section{DISCUSSION}

This is a disease of young women and nulliparous. The incidence in primigravida in our study was $70.11 \%$ as compared to Swain et al $(84 \%)$ and Sultana et al $(41.17 \%){ }^{7,8}$ The incidence is still higher compared to developed countries like the UK, with $0.05 \%$ of total deliveries. The lack of antenatal care was the major contributory factor. We had compared our study with studies conducted in developing countries to conclude in a wider perspective. In our study the incidence of preeclampsia was $2.2 \%$ as compared to the study by Swain et al $(2.2 \%)$ and Sultana et al $(3.23 \%)$. The age group in our study was 20-25 years as compared to Swain et al ( $<20$ years) and Sultana et al (25-34 years). Maternal deaths in our study were $11.11 \%$ as comparable to Sultana et al $(10.29 \%)$ and were high in Swain et al $(29.5 \%)$. The principal maternal mortality risk factors were age, parity, number of convulsions and time between onset of convulsions and admission to hospital. ${ }^{9}$ Neonatal deaths in our centre were $11.2 \%$ as compared to Swain et al $(13.9 \%)$ and Sultana et al $(23.52 \%)$. In our study the incidence of intrauterine deaths (IUD) was $22.4 \%$ comparable to $25 \%$ of Swain et al. (Table 4). Despite eclampsia being recognised since antiquity, consistent management practices are still lacking in developing world. ${ }^{10-12}$ Now a days, the physiopathology of eclampsia remains misunderstood. It is difficult to establish risk factors, the primipaternity being certainly one of these. Eclampsia may occur in an atypical and unforeseeable form in well followed patients, without risk factor. The diagnosis should be done quickly for an adapted treatment and obstetrical management. Despite active research, the aetiology of this disorder remains an enigma. Recent work has, however, provided promising explanations for the causation of the disorder and some of its phenotypes. Evidence indicates that the symptoms of hypertension and proteinuria, upon which the diagnosis of pre-eclampsia is based, have several underlying causes. Nevertheless, the treatment of pre-eclampsia has not changed significantly in over 50 years. ${ }^{13}$ Currently, women at risk are identified on the basis of epidemiological and clinical risk factors, but the diagnostic criteria of pre-eclampsia remain unclear, with no known biomarkers. The treatment of pre-eclampsia is still prenatal care, timely diagnosis, proper management, and timely delivery. The interventions to lengthen pregnancy like treatment for mild hypertension, plasmavolume expansion, and corticosteroid use have not been of proven efficacy. ${ }^{14}$ The randomized trials and studies regarding management of severe pre-eclampsia occurring $<34$ weeks of gestation indicated that anticipant management of the selected patients can ameliorate neonatal outcomes. In case of worsening maternal or fetal condition conducting delivery is the only option. The patients in whom anticipant management is not recommended include are women with eclampsia, renal compromise, HELLP syndrome, pulmonary oedema, disseminated intravascular coagulation (DIC) and abruption of placentae. In women with severe preeclampsia before fetal viability, anticipant management is frequently marked by increased maternal risk and apparently no benefit to the fetus. For women with severe pre-eclampsia before the limit of viability, expectant management has been associated with frequent maternal morbidity with minimal or no benefits to the new-born. Women on anticipant management having severe pre-eclampsia manifesting < 34 weeks of gestation requires in hospital care with strict maternal and fetal monitoring for the improvement of new-born status. ${ }^{15,16}$

\section{CONCLUSIONS}

Preeclampsia is a very common pregnancy associated disorder diagnosed very early. Once eclampsia occurs, carries a high maternal \& perinatal mortality. The key to prevention is proper antenatal check-ups with availability of health facilities to every level of health care. Early detection of high risk cases so that timely action can be taken. Early prediction and diagnosis requires high index of suspicion and comprehensive training of health professionals at all levels of health care. In case of inadequate or untrained staff the case should be promptly referred to tertiary care hospital. The interval between first convulsions to delivery should be minimized to prevent complications. Moreover having pre-eclampsia in one pregnancy is a poor predictor of subsequent pregnancy but a strong predictor for recurrence in future pregnancies. The answer to poor management of eclampsia lies in better education and training of all obstetricians, anaesthetists, midwives, and general practitioners in the diagnosis and treatment of severe preeclampsia and eclampsia. Protocols for the management of fluid balance, antihypertensive and anticonvulsant therapies should be available and reviewed regularly.

\section{Funding: No funding sources}

Conflict of interest: None declared

Ethical approval: The study was approved by the Institutional Ethics Committee

\section{REFERENCES}

1. Working Group Report on High Blood Pressure in Pregnancy. National Institute of Health, National Heart Lung and Blood Institute, National High blood pressure education program, NIH publication. 2000;00-3029.

2. Douglas KA, Redman CWG. Eclampsia in the 
United Kingdom. BMJ. 1994;309:1395-400.

3. Sheth L. Chalmers. Magnesium for preventing and treating eclampsia: time for international action. The Lancet. 1995;359:9321;1872 -3S.

4. WHO. International Collaborative Study of hypertensive disorders of pregnancy. Geographic variation in the incidence of hypertension in pregnancy. Am J Obstet Gynecol. 1998;158:80-3.

5. Bedi N, Kamboj I, Dhillon BS, Saxena BN. Maternal deaths in India- Preventable tragedies (An ICMR task force study). J Obstet Gynecol Ind. 2001;51:8692.

6. Nanda S, Sharma JB et al. Perinatal mortality in eclampsia. J Obstet Gynecol Ind. 1989;39:792-5.

7. Swain S, Ojha KN, Prakash A, Bhatia BD. Maternal and perinatal mortality due to eclampsia. Indian Pediatr 1993;30(6):771-3.

8. Sultana R, Bashir R. Presentation and management outcome of Eclampsia. J Ayub Med Coll Abbottabad 2005;17(2): 59-62.

9. Hussain F, Johanson RB, Jones P. One year survey of maternal mortality associated with eclampsia in Dhaka Medical College Hospital. Journal of
Obstetrics \& Gynaecology. 2000;20(3):239-41.

10. Moodley J, Daya P. Eclampsia a continuing problem in the developing world. Int $\mathbf{J}$ Gynecol Obstet. 1993;44:9-14.

11. Chelsey LC. A short history of eclampsia. Obstet Gynecol. 1974;43:599-602.

12. Salha O, Walker JJ. Modern management of eclampsia. Postgrad Journal. 1999;75(880):78-82.

13. Noris M, Perico N, Remuzzi G. Mechanisms of disease: Pre-eclampsia. Nat Clin Pract Nephrol. 2005;1(2):98-114.

14. Sibai B, Dekker G, Kupferminc M. Pre-eclampsia. Lancet. 2005;365:785-99.

15. Sibai BM. Evaluation and management of severe preeclampsia before 34 weeks' gestation. Am J Obs Gyn. 2011;205(3):191-8.

16. Hernández-Díaz $\mathrm{S}$, Toh $\mathrm{S}$, Cnattingius S. Risk of preeclampsia in first and subsequent pregnancies: prospective cohort study. BMJ. 2009;338:b2255.

Cite this article as: Joshi C, Hatwal D, Mohsin Z. Eclampsia: an Enigma. Int J Reprod Contracept Obstet Gynecol 2016;5:878-81. 